\title{
Role of Serum Ascites Albumin Gradient (SAAG) and Portal Vein Congestion Index as Non-Invasive Methods for Prediction of Esophageal Varices in Cirrhotic Patients
}

\author{
Gamal S. El-Deeb ${ }^{1}$, Shaimaa A. Hassanein ${ }^{2}$, Ibrahim E. Abd-Elmawla ${ }^{3}$, \\ Naglaa S. Elabd ${ }^{1}$ \\ ${ }^{1}$ Department of Tropical Medicine, Faculty of Medicine, Menoufia University, \\ Menoufia, Egypt. \\ ${ }^{2}$ Department of Diagnostic Radiology, Faculty of Medicine - Menoufia University, \\ Menoufia, Egypt. \\ ${ }^{3}$ M.B. B. Ch.
}

Corresponding Author Naglaa Said Elabd

Mobile:

00201092304322

E mail: naglaa_elabd@yahoo. com,

naglaa.alabd.12@med. menofia.edu.eg

Key words: Cirrhosis, esophageal varices, SAAG, portal congestion index
Background and aim: Majority of cirrhotic patients develop varices, the rate of variceal bleeding is $10-30 \%$ yearly with death rate from bleeding is $17-57 \%$. esophagogastroduodenoscopy (EGD) is an invasive and unpleasant technique carrying rare but serious complications. We aimed to investigate the serum ascites albumin gradient (SAAG) and portal vein congestion index (PCI) as non-invasive methods for prediction of esophageal varices $(\mathrm{EV})$ in patients with liver cirrhosis.

Patients and Methods: 125 cirrhotic patients with ascites and no past history of EGD were included. Patients were grouped into; Group I: 38 cirrhotic patients without EV. Group II: 87 cirrhotic patients with EV. Patients were subjected to full clinical evaluation, calculation of SAAG, abdominal ultrasound with a duplex study and measurement of PCI, and Esophagogastroduodenoscopy

\section{INTRODUCTION}

Liver cirrhosis is considered to be a histologic entity that is characterized by the presence of fibrous septae that surround the regenerative nodules of the hepatocytes. Liver cirrhosis represents the end-stage of progressive fibrosis of the liver. A number of insults could give rise to liver cirrhosis, most notably viral hepatitis (HCV and HBV), metabolic causes, alcohol, and nonalcoholic steatohepatitis. The produced architectural distortion noted in endstage liver disease results in increased resistance to portal blood flow in addition, enhanced portal collateral detection and grading of esophageal varices .

Results: Cirrhotic patients with EV had higher SAAG values $(1.85 \pm 0.24 \mathrm{gm} / \mathrm{dl})$ than cirrhotic patients without EV $(1.27 \pm$ $0.15 \mathrm{gm} / \mathrm{dl}$ ). Additionally, cirrhotic patients with EV showed a higher PCI than those without $(0.16 \pm 0.02$ and 0.12 \pm 0.01 respectively). For prediction of $\mathrm{EV}$ in cirrhotic patients, SAAG had AUC $0.986(\mathrm{p}<0.001)$ with cutoff $>1.4$ with sensitivity $97.70 \%$ and specificity $89.47 \%$ and portal congestion index, AUC was $0.974(\mathrm{p}<0.001)$ with cutoff $>0.135$ had sensitivity $90.80 \%$ and specificity $94.74 \%$

Conclusion: SAAG could be used as a non-invasive predictor for the presence of $\mathrm{EV}$ in cirrhotic patients along with SAAG cutoff $>1.4$ requiring clinical attention. Combination of SAAG and PCI had a high ability to predict esophageal varices in cirrhotic patients with AUC 1.000.

circulation, together give a share in portal hypertension [1].

The occurrence of portal hypertension is almost universal, irrespective of the etiology of liver cirrhosis. As the portal pressure overrides a certain threshold, it leads to the development of varices [2]. Hepatic venous pressure gradient (HVPG) is the gold standard method accepted for estimating the severity of portal hypertension [3]. In spite of the advantages of HVPG as safety, and feasibility of the technique, it is invasive and also minor complications ( $<1 \%$ of patients) have been identified including local pain, transient cardiac 
arrhythmias, and vagal reaction [4]. Additionally, HVPG procedure exhibits a low rate of acceptance among chronic liver disease patients, moreover, it necessitates technical expertise who typically present at tertiary medical centers [5].

Approximately fifty percent of cirrhotic patients develop varices frequently in the distal $2-5 \mathrm{~cm}$ of the esophagus. Yearly, the rate of bleeding from varices is around 10 to 30 percent yearly. As well as the death rate from this bleeding is $17-57 \%$ [2]. As a result, when liver cirrhosis is first diagnosed, all patients should start to be screened for the presence of gastroesophageal varices.

Esophagogastroduodenoscopy (EGD) is considered as the gold-standard method for screening of varices, nevertheless, the primary disadvantages are that, EGD is an invasive procedure which invariably induces patient discomfort and many patients decline it, additionally, the cost is relatively high. Besides, the diagnosis and classification of varices, particularly small gastric and esophageal varices, are subject to inter-observer variability [6].

Serum ascites albumin gradient (SAAG) was developed as an approach, to distinguish ascites into two groups; ascites with high SAAG (SAAG $\geq 1.1 \mathrm{~g} / \mathrm{dl}$ ) in patients with ascites linked to portal hypertension and low SAAG ascites (SAAG $<1.1 \mathrm{~g} / \mathrm{dl}$ ) in patients whom ascites not related to portal hypertension. SAAG foremost mirrors the oncotic pressure that is exerted by serum albumin over albumin in ascitic fluid that genuinely equalizes the high hydrostatic pressure gradient amidst the portal bed and the ascitic fluid. Diagnostic paracentesis is indicated for all patients with new onset ascites, particularly grade 2 or 3 ascites as well as those admitted to a hospital with cirrhosis complications [7].

The clinical application of an ultrasonic duplex system comprising a B-mode probe and pulsed Doppler flowmeter in patients with liver cirrhosis or idiopathic portal hypertension has made it possible for quantitative measurement of blood flow in deep-seated blood vessels, including assessment of blood flow in the portal vein [8]. So in this study we pursued to assess the role of serum ascites albumin gradient (SAAG) and portal vein congestion index as non-invasive methods in predicting esophageal varices in cirrhotic patients with ascites and to clear out their relation with the grade of esophageal varices.

\section{PATIENTS AND METHODS}

The present work is a prospective research that was carried out in Tropical Medicine Department in collaboration with Diagnostic Radiology Department, Faculty of Medicine, Menoufia University. One hundred and twenty-five cirrhotic patients with no past history of esophagogastroduodenoscopy were included, they were selected from May 2018 to July 2020. Diagnosis of liver cirrhosis was done by clinical examination, ultrasound finding as well as laboratory evaluations. Based on upper endoscopic finding, patients were grouped into one of two groups; Group I: included 38 cirrhotic patients without esophageal varices $(\mathrm{EV})$, they were $22(59.7 \%)$ males and $16(42.1 \%)$ females with mean age (62.89 \pm 8.33$)$ and Group II: comprised 87 cirrhotic patients with esophageal varices, they were $36(41.1 \%)$ males and 51 (58.6\%) females.

For all patients, history and clinical evaluation was collected. Patients with one of the following conditions were excluded; ascites due to any etiology other than cirrhosis, past history of hematemesis or melena related to portal hypertension, space-occupying lesion in the liver, portal vein thrombosis. Also patients on a beta-blocker or a long-acting nitrate treatment and patients who underwent trans-jugular intrahepatic portosystemic shunt (TIPS) or surgery for portal hypertension were excluded.

Ethical Approval: For all participants an explanation about the study was provided together with informed consents were acquired from each one before enlisted in the study. The study was assured by the ethical committee of Faculty of Medicine, Menoufia University and performed under the direction of the Helsinki Declaration.

Esophagogastroduodenoscopy: EGD was done for all participants for detection esophageal varices (EV), fundal varices, portal hypertensive gastropathy (PHG) and other significant finding. Grading of esophageal varices (EV) into 4 grads was done regarding their size and depending on the degree of protrusion of the varices into the lumen of esophagus at the esophageo-gastric junction when the esophagus was maximally relaxed [9].

Laboratory investigations: Laboratory evaluations comprised complete blood count, liver function tests (aspartate transferase (AST) 
alanine transferase (ALT), serum albumin, prothrombin time, the international normalized ratio (INR), total \& direct bilirubin) and kidney function tests and serum electrolytes. Diagnostic paracentesis was done for all patients; $30 \mathrm{~mL}$ of ascitic fluid was taken under complete aseptic condition (either bedside or ultrasound guide in mild cases) for assessment of ascitic fluid albumin concentration, total protein, cell count with differential. Detection of serological markers of HCVAb and HBsAg by enzyme linked immunosorbent assay (ELISA) to assess the etiology of cirrhosis. Then we calculated the serum ascetic albumin gradient (SAAG)

SAAG = serum albumin - ascites albumin [10]

Radiological evaluation: Abdominal ultrasonography was done using Siemens Sonolone Sienna sonography for all patients. All participants were held fasting before ultrasonography for at least 6 hours. All patients underwent color Doppler ultrasonic examination. The main Doppler finding have been evaluated by the same operator and by the same equipment (with a 3.5-5 MHz curve - array transducer, G-50 Siemens).

Assessment of blood flow and patency of the portal vein: B-mode imaging was used to determine the PV anatomy. Portal vein was recognized by the following; the splenic vein to the right till its junction with the superior mesenteric vein (SMV). This method dodged the confusion of PV with the inferior vena cava or with the bile duct. Whilst, when the PV is troublesome to be observed in the supine position, the patient was checked in the left lateral position.

\section{Estimation of portal hemodynamic parameters:}

1-Cross-sectional area: PV cross-sectional area was measured from the B-mode image of PV while scanning perpendicular to the long axis of the PV.

2-Portal vein blood velocity $(\mathrm{cm} / \mathrm{s})$ : Main portal vein blood velocity was assessed in its midportion, as the hepatic artery (HA) crosses the Portal Vein, on oblique subcostal scans. The axial size of the sample volume was adjusted to encompass the lumen of the Portal Vein in its entirety. The angle between the Doppler beam and the vessel's long axis was kept below $60^{\circ}$. On samples of the Doppler signal lasting longer than 4 seconds, the portal vein blood velocity was automatically estimated.

\section{3- Congestion index of the portal vein (CI) :}

Congestion index of the portal vein $(\mathrm{Cl})=$

Portal vein cross-sectional area

Mean velocity of the portal vein

[11]

\section{Statistical analysis of the data}

Data of this study were supplied to the computer and analyzed utilizing IBM SPSS software package version 20.0. (Armonk, NY: IBM Corp). Number and percent were used to depict qualitative data. The normality of distribution was verified using the Kolmogorov-Smirnov test. The quantitative data were depicted utilizing range (minimum and maximum), mean, standard deviation and median. For categorical variables, Chi-square test was used to compare between different groups. Correction for chi-square when more than $20 \%$ of the cells have expected count less than five the Fisher's Exact or Monte Carlo correction was employed. To compare between two studied groups of normally distributed quantitative variables the Student t-test was applied. While to compare between two studied groups of abnormally distributed quantitative variables Mann Whitney test is applied. The area under the ROC (Receiver operating characteristic curve) indicates the diagnostic performance of the test with an area more than 50\% awards reasonable performance and an area about $100 \%$ is the preferable performance for the test. As well the ROC curve permits a comparison of performance between two tests. F-test (ANOVA); For normally distributed quantitative variables, to compare between more than two groups. To correlate between two normally distributed quantitative variables Pearson coefficient is used. To detect the most independent/ affecting factor for predicting esophageal varices regression analysis is applied. The significance of the acquired results was assessed at a $5 \%$ level.

\section{RESULTS}

Table 1 summarized the comparison between the two patient groups regarding the demographic data: 38 patients ranged in age between 45- 88 years with a mean age of $62.89 \pm 8.33$ years for Group I and 87 patients ranged in age between $40-75$ years with a mean age $60.24 \pm 5.86$ years 
for Group II. Group I had 22 males and 16 females, while Group II had 36 males and 51 females. We noticed that the mean of age as well as gender distributions did not differ between the two groups.

Concerning the history and general examination; hepatic encephalopathy, jaundice and L.L oedema were considerably different between the two groups $(\mathrm{p}=0.002,0.039$, and 0.012 respectively). Group II; cirrhotic patients with esophageal varices displayed a higher prevalence of hepatic encephalopathy jaundice, and L.L oedema than cirrhotic patients without esophageal varices. While bleeding tendency, ecchymosis and spider naevi did not significantly differ between the two groups $(p=0.475,0.575$ and 0.613 respectively). Child Pugh score was significantly different between the two groups ( $\mathrm{p}$ $=00.014)$ where in cirrhotic patients with esophageal varices, Child Pugh score C represents $63.2 \%$ of Group II compared to $39.5 \%$ in cirrhotic patients without esophageal varices (table 1).

Abdominal ultrasound displayed that, splenic collaterals were significantly more frequent in GI than in GII $(\mathrm{p}=<0.001)$ as shown in table $\mathbf{1}$ and figure 1A, however, the grade of ascites, the size of spleen, and the size of liver did not differ between the two groups $(\mathrm{p}=0.123,0.568$, and 0.795 respectively).

Regarding the cross section area of Portal Vein, peak velocity, and Portal Congestion Index, Doppler ultrasonic examination showed that, there was a considerable difference between the two groups $(\mathrm{p}<0.001)$. We found that cirrhotic patients with esophageal varices showed a higher Portal Vein cross section area as well as Portal Congestion Index than in those without esophageal varices. However, a lower peak velocity was found in cirrhotic patients with esophageal varices than in those without as presented in table 1 and figure 1B. Esophagogastroduodenoscopy showed the grads of esophageal varices in GII. Additionally, portal hypertension gastropathy did not significantly differ between the two studied groups ( $\mathrm{p}=$ 0.058) (table 2, figures 1C and 1D)

Cirrhotic patients with esophageal varices showed a clearly lower platelet count than patients without varices $(p<0.001)$ as shown in figure $\mathbf{2 A}$, while hemoglobin concentration and white blood cell count did not vary between the two patient groups $(\mathrm{p}=00.895$ and 0.974 respectively). Regarding AST, ALT, INR and total bilirubin, there was a statistically nonsignificant difference between both groups. However, serum albumin as well as ascitic fluid albumin were found to be significantly lower in cirrhotic patients with EV than in those without $\mathrm{EV}(\mathrm{p}<0.001)$ (figures $\mathbf{2 B}$ and 2C). The values of SAAG were considerably higher in Group II (mean SAAG $=1.85 \pm 0.24$ ) than in Group I (mean SAAG $=1.27 \pm 0.15$ ) with $\mathrm{p}<0.001$ (figure 2D). Cirrhotic patients with esophageal varices showed lower serum $\mathrm{Na}$ and higher serum K compared to Group I, ( $p$ was <0.001 and 0.014 respectively) as presented in table 2.

Table 3 and figure $\mathbf{3 A}$ showed ROC curve for SAAG for detection of esophageal varices: AUC was 0.986 ( $p<0.001)$ with Cut off $>1.4$ had a high ability to predict esophageal varices in cirrhotic patients with Sensitivity $97.70 \%$ and Specificity of $89.47 \%$. Also, figure 3A showed ROC curve for portal congestion index for the prediction of esophageal varices: AUC was 0.974 ( $\mathrm{p}<0.001$ ) with cut off $>0.135$ had sensitivity $90.80 \%$ and specificity of $94.74 \%$. Additionally, table 3 and figure 3B presents ROC curve for the combination of SAAG and portal congestion index for the prediction of esophageal varices in cirrhotic patients: AUC was $1.000(p<0.001)$ with sensitivity $100.0 \%$ and specificity of $100.0 \%$.

A significant relation was detected between SAAG with history of hepatic encephalopathy, the existence of portal hypertensive gastropathy (PHG) and the grade of esophageal varices ( $\mathrm{p}=$ $0.024,0.045$, and 0.001 respectively) while, no significant relation was found with Child Pugh score or grade of ascites $(p=0.417$, and 0.052 respectively) in Group II (table 4 and figure 3C).

Table 5 represented the relation between portal congestion index with clinical and endoscopic findings in Group II, we found out a significant relation between portal congestion index with history of hepatic encephalopathy, the existence of PHG, the grade of esophageal varices and grade of ascites $(p=0.032,0.001,0.002,0.029$ respectively) while, no significant relation with Child Pugh score $(\mathrm{p}=0.625)$ in Group II.

SAAG showed a significant negative correlation with PLT $(\mathrm{r}=-0.401$ and $\mathrm{p}=<0.001)$. Besides, a significant negative correlation was found between portal congestion index with PLT and with serum $\mathrm{Na}(\mathrm{r}=-0.262$ and -0.220 respectively and $\mathrm{p}=0.014$ and 0.040 respectively). 
Analyzing the risk association of both portal congestion index and SAAG with the presence of esophageal varices, our study explored that both could be considered as risk factors for predicting esophageal varices in cirrhotic patient with crude OR 5.626 [95\% C.I] 2.670-11.853 and OR 6.768 [95\% C.I] 2.782-16.461 respectively, moreover with adjusted odds ratio by age and sex OR
5.615 and 9.035 respectively in addition with adjusted odds ratio by age, sex, hepatic encephalopathy, splenic collaterals, platelet count and Child Pugh score OR were 11.079 [95\% C.I] 2.680 - 45.799 and 18.892 [95\% C.I] $3.235-110.322$ respectively as shown in table 6.

Table (1): Comparison between the two studied groups according to demographic data, history, examination and ultrasound finding.

\begin{tabular}{|c|c|c|c|c|}
\hline & $\begin{array}{l}\text { Group I } \\
(\mathbf{n}=38)\end{array}$ & $\begin{array}{c}\text { Group II } \\
(\mathbf{n}=\mathbf{8 7})\end{array}$ & The test of Sig. & $\mathbf{p}$ \\
\hline \multicolumn{5}{|l|}{$\overline{\operatorname{Sex}}$} \\
\hline Male & $22(59.7 \%)$ & $36(41.4 \%)$ & \multirow{2}{*}{$\chi^{2}=2.901$} & \multirow{2}{*}{0.089} \\
\hline \multirow{2}{*}{\multicolumn{5}{|c|}{ Age (years) }} \\
\hline & & & & \\
\hline Mean \pm SD & $62.89 \pm 8.33$ & $60.24 \pm 5.86$ & \multirow{2}{*}{$\mathrm{t}=1.780$} & \multirow{2}{*}{0.081} \\
\hline Median (Min. - Max.) & $63(45-88)$ & $60(40-75)$ & & \\
\hline History of Hepatic encephalopathy & $4(10.5 \%)$ & $33(37.9 \%)$ & $\chi^{2}=9.532^{*}$ & $0.002^{*}$ \\
\hline \multicolumn{5}{|l|}{ History of Bleeding tendency } \\
\hline $\begin{array}{l}\text { No } \\
\text { Yes }\end{array}$ & $\begin{array}{l}21(55.3 \%) \\
17(447 \%)\end{array}$ & $54(62.1 \%)$ & $\chi^{2}=0.510$ & 0.475 \\
\hline \multicolumn{5}{|l|}{ Child Pugh Score } \\
\hline $\begin{array}{l}\mathrm{B} \\
\mathrm{C}\end{array}$ & $\begin{array}{l}23(60.5 \%) \\
15(39.5 \%)\end{array}$ & $\begin{array}{l}32(36.8 \%) \\
55(63.2 \%)\end{array}$ & $\chi^{2}=6.052^{*}$ & $0.014^{*}$ \\
\hline \multicolumn{5}{|l|}{ Ecchymosis } \\
\hline $\begin{array}{l}\text { No } \\
\text { Yes }\end{array}$ & $\begin{array}{l}26(68.4 \%) \\
12(31.6 \%)\end{array}$ & $\begin{array}{l}55(63.2 \%) \\
32(81.6 \%)\end{array}$ & $\chi^{2}=0.314$ & 0.575 \\
\hline \multicolumn{5}{|l|}{ L.L oedema } \\
\hline $\begin{array}{l}\text { No } \\
\text { Yes }\end{array}$ & $\begin{array}{l}15(39.5 \%) \\
23(60.5 \%)\end{array}$ & $\begin{array}{l}16(18.4 \%) \\
71(81.6 \%)\end{array}$ & $\chi^{2}=6.304^{*}$ & $0.012^{*}$ \\
\hline Jaundice & $10(26.3 \%)$ & $40(46 \%)$ & $\chi^{2}=4.260^{*}$ & $0.039^{*}$ \\
\hline Spider naevi & $8(21.1 \%)$ & $15(17.2 \%)$ & $\chi^{2}=0.256$ & 0.613 \\
\hline \multicolumn{5}{|l|}{ Ascites } \\
\hline Mild to moderate & $32(84.2 \%)$ & $62(71.3 \%)$ & \multirow{2}{*}{$\chi^{2}=2.377$} & \multirow{2}{*}{0.123} \\
\hline Spleen (US) & $6(15.8 \%)$ & $25(28.7 \%)$ & & \\
\hline Splenic collaterals & & & & \\
\hline $\begin{array}{l}\text { No } \\
\text { Yes }\end{array}$ & $23(60.5 \%)$ & $23(26.4 \%)$ & \multirow[t]{2}{*}{$\chi^{2}=13.215^{*}$} & $<0.001^{*}$ \\
\hline \multicolumn{4}{|l|}{ Size } & \\
\hline Enlarged & $31(81.6 \%)$ & $67(77 \%)$ & \multirow{2}{*}{$\chi^{2}=0.326$} & \multirow{2}{*}{0.568} \\
\hline Not enlarged & $7(18.4 \%)$ & $20(23 \%)$ & & \\
\hline \multicolumn{5}{|l|}{ Liver (US) } \\
\hline Size & & & & \\
\hline Average & $7(18.4 \%)$ & $16(18.4 \%)$ & & \\
\hline Enlarged & $5(13.2 \%)$ & $8(9.2 \%)$ & $\chi^{2}=0.459$ & 0.795 \\
\hline Shrunken & $26(68.4 \%)$ & $63(72.4 \%)$ & & \\
\hline Portal Vein (US and Doppler) & & & & \\
\hline Cross section area & & & & \\
\hline Mean \pm SD. & $1.73 \pm 0.14$ & $1.87 \pm 0.12$ & $\mathrm{t}=5.949^{*}$ & $<0.001^{*}$ \\
\hline Peak velocity & & & & \\
\hline $\begin{array}{l}\text { Mean } \pm \text { SD. } \\
\text { Median (Min. - Max.) }\end{array}$ & $14.92 \pm 1.14$ & $11.65 \pm 1.38$ & $\mathrm{t}=12.777^{*}$ & $<0.001^{*}$ \\
\hline $\begin{array}{l}\text { Median (Min. - Max.) } \\
\text { Congestion index }\end{array}$ & $15.2(12.6-16.5)$ & & & \\
\hline $\begin{array}{l}\text { Mean } \pm \text { SD. } \\
\text { Median (Min. - Max.) }\end{array}$ & $\begin{array}{c}0.12 \pm 0.01 \\
0.12(0.10-0.14)\end{array}$ & $\begin{array}{c}0.16 \pm 0.02 \\
0.16(0.12-0.23)\end{array}$ & $\mathrm{t}=14.576^{*}$ & $<0.001^{*}$ \\
\hline
\end{tabular}

$\chi 2$ : Chi square test t: Student t-test US: ultrasound

$\mathrm{p}: \mathrm{p}$ value for comparing between the two studied groups

*: Statistically significant at $\mathrm{p} \leq 0.05$ 
Table (2): Comparison between the two studied groups according to portal hypertensive gastropathy and laboratory parameters.

\begin{tabular}{|c|c|c|c|c|}
\hline & $\begin{array}{l}\text { Group I } \\
(\mathbf{n}=\mathbf{3 8})\end{array}$ & $\begin{array}{c}\text { Group II } \\
(\mathbf{n}=87)\end{array}$ & The test of Sig. & $\mathbf{p}$ \\
\hline \multicolumn{5}{|l|}{$\begin{array}{l}\text { Portal hypertension } \\
\text { hysion }\end{array}$} \\
\hline \multicolumn{5}{|l|}{ Gastropathy } \\
\hline No & $27(71.1 \%)$ & $46(52.9 \%)$ & \multirow{2}{*}{$\chi^{2}=3.598$} & \multirow{2}{*}{0.058} \\
\hline Yes & $11(28.9 \%)$ & $41(47.1 \%)$ & & \\
\hline \multicolumn{5}{|l|}{ HB (gm/dl) } \\
\hline Mean \pm SD & $10.62 \pm 1.74$ & $10.66 \pm 1.23$ & \multirow{2}{*}{$\mathrm{t}=0.132$} & \multirow{2}{*}{0.895} \\
\hline Median (Min. - Max.) & $11(6.1-14)$ & $11(6.3-12.9)$ & & \\
\hline \multicolumn{5}{|l|}{ WBCs $\left(10^{3} / \mathrm{mm}^{3}\right)$} \\
\hline Mean \pm SD & $5.32 \pm 1.62$ & $5.38 \pm 1.81$ & \multirow{2}{*}{$\mathrm{U}=1647.0$} & \multirow{2}{*}{0.974} \\
\hline Median (Min. - Max.) & $5(2.1-8.2)$ & $5(2.5-10)$ & & \\
\hline \multicolumn{5}{|l|}{$\operatorname{PLT}\left(10^{3} / \mathrm{mm}^{3}\right)$} \\
\hline Mean \pm SD & $94.0 \pm 11.77$ & $70.49 \pm 11.01$ & \multirow{2}{*}{$\mathrm{t}=10.754^{*}$} & \multirow{2}{*}{$<0.001^{*}$} \\
\hline Median (Min. - Max.) & $94(60-120)$ & $70(41-97)$ & & \\
\hline \multicolumn{5}{|l|}{$\operatorname{AST}(\mathbf{I U} / \mathbf{L})$} \\
\hline Mean \pm SD & $50.42 \pm 14.48$ & $50.48 \pm 27.89$ & \multirow{2}{*}{$\mathrm{U}=1410.0$} & \multirow{2}{*}{0.192} \\
\hline Median (Min. - Max.) & $50(23-94)$ & $43(12.8-138)$ & & \\
\hline \multicolumn{5}{|l|}{ ALT (IU/L) } \\
\hline Mean \pm SD & $30.53 \pm 15.85$ & $29.76 \pm 14.40$ & \multirow{2}{*}{$\mathrm{U}=1632.0$} & \multirow{2}{*}{0.910} \\
\hline Median (Min. - Max.) & $27(10-80)$ & $26(8-94)$ & & \\
\hline \multicolumn{5}{|l|}{ INR } \\
\hline Mean \pm SD & $1.33 \pm 0.23$ & $1.34 \pm 0.25$ & \multirow{2}{*}{$\mathrm{t}=0.133$} & \multirow{2}{*}{0.894} \\
\hline Median (Min. - Max.) & $1.3(1.08-2.1)$ & $1.3(1-2.1)$ & & \\
\hline \multicolumn{5}{|l|}{ Total Bilirubin (mg/dl) } \\
\hline Mean \pm SD & $1.93 \pm 0.82$ & $2.29 \pm 1.17$ & \multirow{2}{*}{$\mathrm{U}=1444.0$} & \multirow{2}{*}{0.261} \\
\hline Median (Min. - Max.) & $1.7(0.50-3.5)$ & $2(0.90-5)$ & & \\
\hline \multicolumn{5}{|l|}{ Serum albumin (gm/dl) } \\
\hline Mean \pm SD & $2.71 \pm 0.26$ & $2.16 \pm 0.30$ & & $<0 \Omega 01^{*}$ \\
\hline Median (Min. - Max.) & $2.7(1.8-3.3)$ & $2.1(1.6-3.2)$ & $t=9.670$ & $<0.001$ \\
\hline Ascitic fluid albumin & & & & \\
\hline Mean \pm SD & $1.44 \pm 0.28$ & $0.32 \pm 0.18$ & $\mathrm{U}-250^{*}$ & $<0 \Omega 01$ * \\
\hline Median (Min. - Max.) & $1.4(0.80-2.3)$ & $0.30(0.10-0.90)$ & $\mathrm{U}=2.50$ & $<0.001$ \\
\hline SAAG & & & & \\
\hline Mean \pm SD & $1.27 \pm 0.15$ & $1.85 \pm 0.24$ & $t=13826^{*}$ & $<0001^{*}$ \\
\hline Median (Min. - Max.) & $1.3(1-1.5)$ & $1.9(1.3-2.4)$ & $\mathrm{t}=13.826$ & $<0.001$ \\
\hline Serum Na & & & & \\
\hline Mean \pm SD & $135.9 \pm 1.85$ & $132.1 \pm 4.0$ & $t=7386^{*}$ & $<0001 *$ \\
\hline Median (Min. - Max.) & $136(133-140)$ & $133(121-139)$ & $\mathrm{t}=1.386$ & $<0.001$ \\
\hline Serum K & & & & \\
\hline Mean \pm SD & $3.96 \pm 0.40$ & $4.23 \pm 0.58$ & $\mathrm{U}=11975^{*}$ & $0.014^{*}$ \\
\hline Median (Min. - Max.) & $4(3.1-4.8)$ & $4.1(3.2-6.5)$ & $\mathrm{U}=1191.5$ & 0.014 \\
\hline
\end{tabular}

Hb: hemoglobin concentration, PLT: platelet count, WBCs: white blood cells.

ALT: Alanine aminotransferase, AST: aspartate aminotransferase, INR: international normalized ratio.

SAAG: serum-ascites albumin gradient

U: Mann Whitney test

$\mathrm{p}$ : $\mathrm{p}$ value for comparing between the two studied groups

\section{t: Student t-test}

*: Statistically significant at $\mathrm{p} \leq 0.05$ 


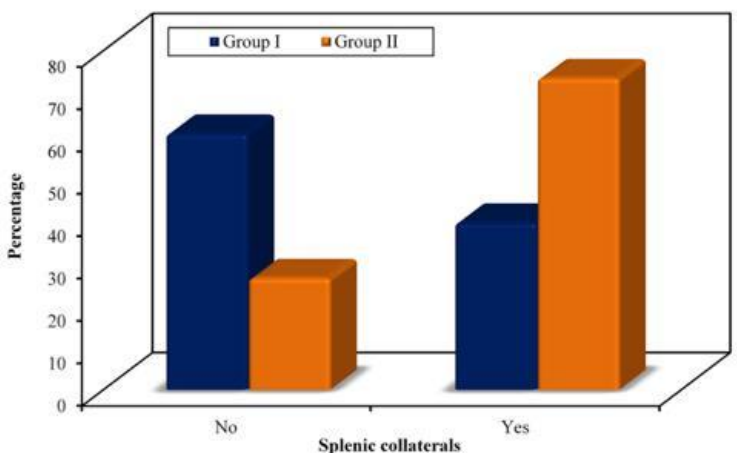

A

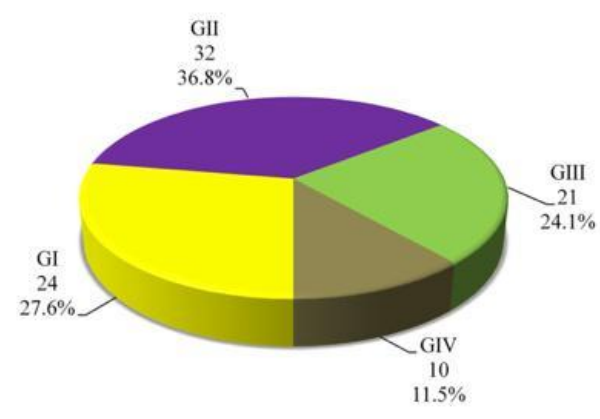

C

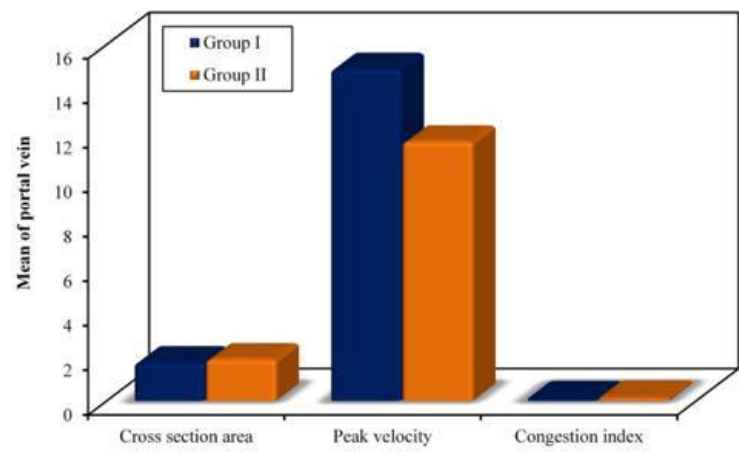

B

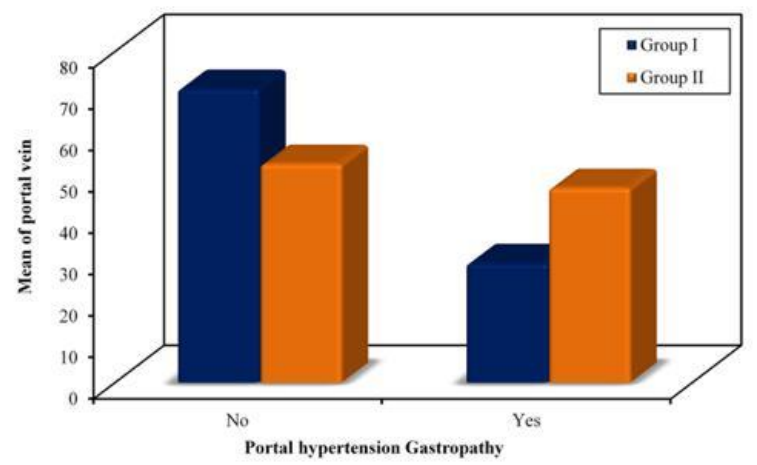

D

Figure 1; (A): Comparison between the two studied groups according to Splenic collaterals, (B): Comparison between the two studied groups according to portal vein (cross sectional area, peak velocity, congestion index), (C): Distribution of the studied cases according to esophageal varices grade in cirrhotic patients with esophageal varices group (GII), and (D): Comparison between the two studied groups according to the presence of portal hypertension gastropathy 


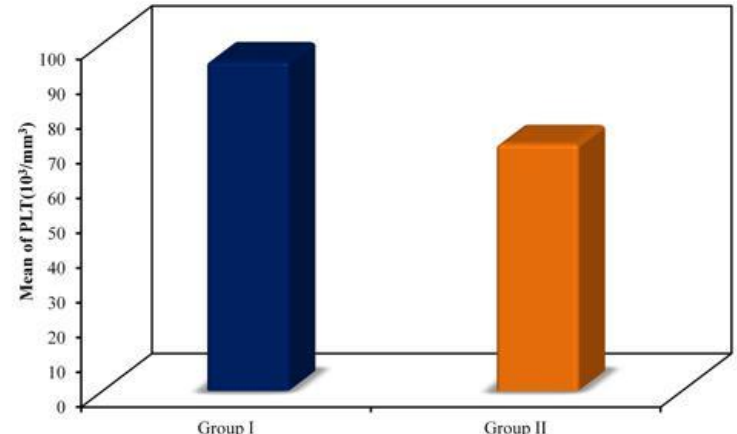

A

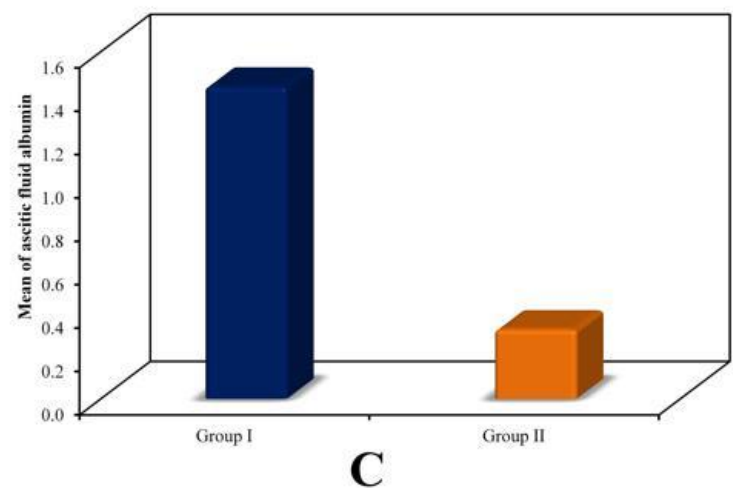

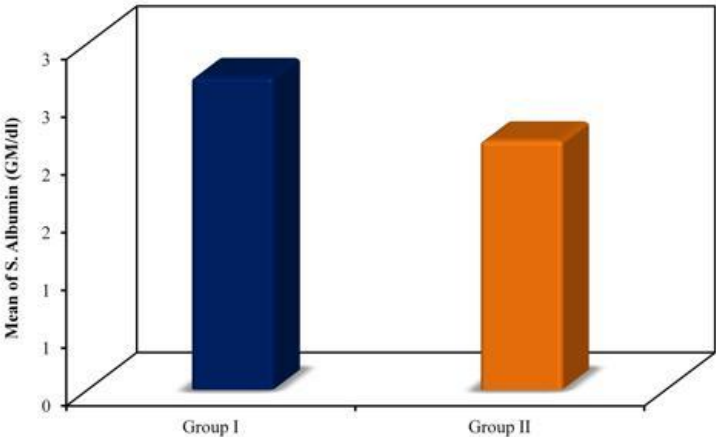

B

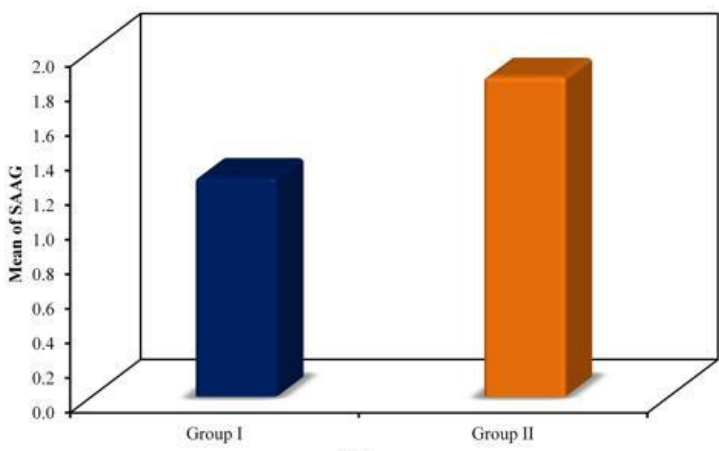

D

Figure 2; (A): Comparison between the two studied groups according to platelet count (103/mm3), (B): Comparison between the two studied groups according to serum albumin (GM/dl), (C): Comparison between the two studied groups according to ascitic fluid albumin, and (D): Comparison between the two studied groups according to SAAG

Table (3): Agreement (sensitivity, specificity) for SAAG, Congestion index and the combination of both for prediction of esophageal varices $(n=87)$.

\begin{tabular}{lcccccccc}
\hline & AUC & p & 95\% C.I & \multicolumn{2}{c}{ Cut off $^{*}$ Sensitivity } & Specificity & PPV & NPV \\
\hline SAAG & 0.986 & $<0.001^{*}$ & $0.970-1.002$ & $>1.4$ & 97.70 & 89.47 & 95.5 & 94.4 \\
PCI & 0.974 & $<0.001^{*}$ & $0.952-0.996$ & $>0.135$ & 90.80 & 94.74 & 97.5 & 81.8 \\
SAAG + PCI & 1.000 & $<0.001^{*}$ & $1.0-1.0$ & & & & & \\
\hline
\end{tabular}

AUC: Area Under a Curve

CI: Confidence Intervals

NPV: Negative predictive value

$\mathrm{p}$ value: Probability value

SAAG: serum-ascites albumin gradient

PPV: Positive predictive value

PCI: Portal congestion index

*: Statistically significant at $\mathrm{p} \leq 0.05$

\#Cut off was choose according to Youden index 
Table (4): Relation between SAAG with clinical and endoscopic parameters Group II ( $\mathrm{n}=87)$.

\begin{tabular}{lccccc}
\hline & N & Median (Min. - Max.) & Mean \pm SD. & $\begin{array}{c}\text { The test of } \\
\text { Sig. }\end{array}$ & p \\
\hline $\begin{array}{l}\text { Hepatic encephalopathy } \\
\quad \text { No }\end{array}$ & $\mathbf{5 4}$ & $1.9(1.3-2.1)$ & $1.81 \pm 0.21$ & $\mathrm{t}=$ & \\
$\quad$ Yes & $\mathbf{3 3}$ & $1.8(1.6-2.4)$ & $1.92 \pm 0.26$ & $2.297^{*}$ & $0.024^{*}$ \\
$\begin{array}{l}\text { Child Pugh Score } \\
\quad \text { B }\end{array}$ & $\mathbf{3 2}$ & $1.9(1.3-2.4)$ & $1.88 \pm 0.26$ & & \\
$\quad$ C & $\mathbf{5 5}$ & $1.8(1.5-2.4)$ & $1.83 \pm 0.23$ & $\mathrm{t}=0.816$ & 0.417 \\
Ascites & & & & \\
$\quad$ Mild to moderate & $\mathbf{6 2}$ & $1.9(1.3-2.4)$ & $1.88 \pm 0.24$ & $\mathrm{t}=$ & 0.052 \\
$\quad$ Massive & $\mathbf{2 5}$ & $1.7(1.5-2.4)$ & $1.77 \pm 0.24$ & 1.975 & \\
$\begin{array}{l}\text { Portal hypertensive gastropathy } \\
\quad \text { No }\end{array}$ & $\mathbf{4 6}$ & $1.9(1.3-2.1)$ & $1.80 \pm 0.20$ & $\mathrm{t}=$ & \\
$\quad$ Yes & $\mathbf{4 1}$ & $1.9(1.5-2.4)$ & $1.90 \pm 0.27$ & $2.032^{*}$ & $0.045^{*}$ \\
$\quad$ Esophageal varices grade & $\mathbf{2 4}$ & $1.8(1.3-2.1)$ & $1.79 \pm 0.21$ & & \\
$\quad$ G1 & $\mathbf{3 2}$ & $1.9(1.5-2.1)$ & $1.80 \pm 0.17$ & $\mathrm{~F}=$ & \\
$\quad$ G2 & $\mathbf{2 1}$ & $1.8(1.6-2.4)$ & $1.87 \pm 0.26$ & $5.751^{*}$ & $0.001^{*}$ \\
$\quad$ G3 & $\mathbf{1 0}$ & $2.2(1.6-2.4)$ & $2.11 \pm 0.30$ & & \\
$\quad$ G4 & & & & & \\
\hline
\end{tabular}

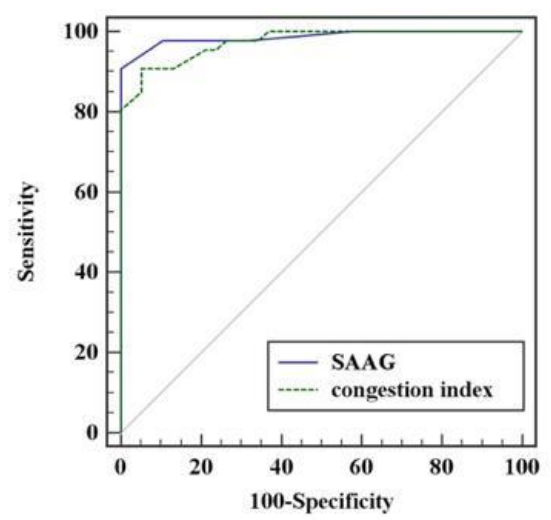

A

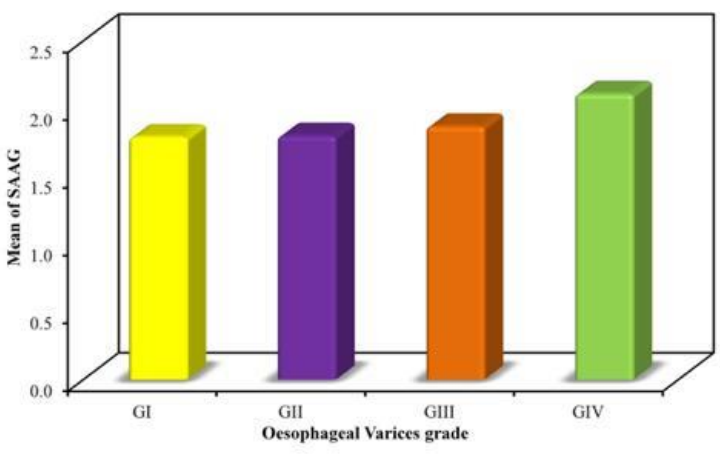

C

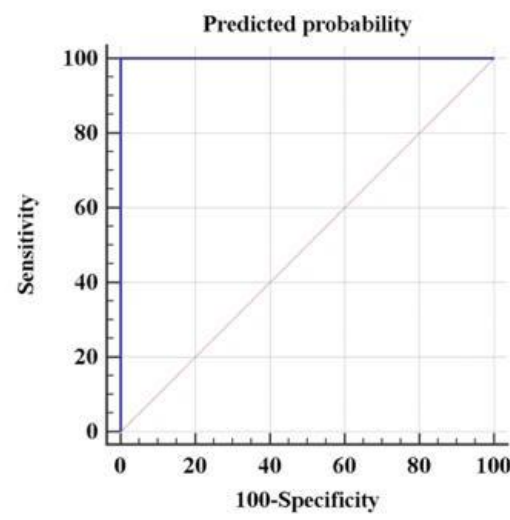

B

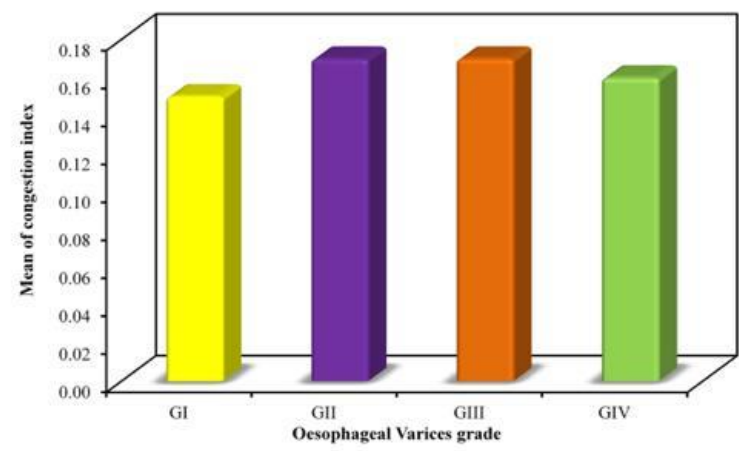

D

Figure 3 (A): ROC curve for SAAG and portal congestion index (PCI) for detection of esophageal varices, (B): ROC curve for combination of SAAG and PCI for detection of esophageal varices, (C): 
Relation between SAAG and esophageal varices grade in Group II, and (D): Relation between portal congestion index and esophageal varices grade in Group II

Table (5): Relation between PCI with clinical and endoscopic parameters in Group II ( $\mathrm{n}=87)$.

\begin{tabular}{|c|c|c|c|c|c|}
\hline & $\mathbf{N}$ & Median (Min. - Max.) & Mean \pm SD. & $\begin{array}{c}\text { The test of } \\
\text { Sig. }\end{array}$ & $\mathbf{p}$ \\
\hline \multicolumn{6}{|c|}{ Hepatic encephalopathy } \\
\hline No & 54 & $0.16(0.12-0.20)$ & $0.16 \pm 0.02$ & $\mathrm{t}=$ & \multirow{2}{*}{$0.032^{*}$} \\
\hline Yes & 33 & $0.18(0.13-0.23)$ & $0.17 \pm 0.03$ & $2.184^{*}$ & \\
\hline \multicolumn{6}{|l|}{ Child Pugh Score } \\
\hline B & 32 & $0.16(0.12-0.20)$ & $0.16 \pm 0.02$ & $\mathrm{t}=$ & \multirow{2}{*}{0.625} \\
\hline $\mathrm{C}$ & 55 & $0.17(0.13-0.23)$ & $0.17 \pm 0.02$ & 0.492 & \\
\hline \multicolumn{6}{|l|}{ Ascites } \\
\hline Mild to moderate & 62 & $0.16(0.12-0.23)$ & $0.16 \pm 0.02$ & $t=$ & \multirow{2}{*}{$0.029^{*}$} \\
\hline Massive & 25 & $0.17(0.15-0.20)$ & $0.17 \pm 0.02$ & $2.226^{*}$ & \\
\hline \multicolumn{6}{|l|}{$\begin{array}{l}\text { Portal hypertensive } \\
\text { gastropathy }\end{array}$} \\
\hline No & 46 & $0.16(0.12-0.20)$ & $0.16 \pm 0.02$ & $t=$ & \multirow{2}{*}{$0.001^{*}$} \\
\hline Yes & 41 & $0.17(0.13-0.23)$ & $0.17 \pm 0.02$ & $3.397^{*}$ & \\
\hline \multicolumn{6}{|c|}{ Esophageal varices grade } \\
\hline G1 & 24 & $0.14(0.12-0.20)$ & $0.15 \pm 0.02$ & & \multirow{4}{*}{$0.002^{*}$} \\
\hline $\mathrm{G} 2$ & 32 & $0.16(0.13-0.23)$ & $0.17 \pm 0.02$ & $\mathrm{~F}=$ & \\
\hline G3 & 21 & $0.18(0.13-0.23)$ & $0.17 \pm 0.02$ & $5.493^{*}$ & \\
\hline G4 & 10 & $0.15(0.14-0.20)$ & $0.16 \pm 0.02$ & & \\
\hline
\end{tabular}

t: Student t-test, F: F for ANOVA test

Table (6): Odd`s ratio for SAAG and Portal Congestion Index.

\begin{tabular}{|l|c|c|c|c|c|c|}
\hline & \multicolumn{2}{|c|}{ Crude Odd`s ratio } & \multicolumn{2}{c|}{ Model A } & \multicolumn{2}{c|}{ Model B } \\
\cline { 2 - 7 } & $\mathbf{p}$ & OR(95\% C.I $)$ & $\mathbf{p}$ & OR(95\% C.I $)$ & $\mathbf{p}$ & OR(95\% C.I) \\
\hline PCI & $<0.001^{*}$ & $5.626(2.670-11.853)$ & $<0.001^{*}$ & $5.649(2.696-11.836)$ & $0.001^{*}$ & $11.079(2.680-45.799)$ \\
\hline SAAG & $<0.001^{*}$ & $6.768(2.782-16.461)$ & $<0.001^{*}$ & $9.035(2.941-27.758)$ & $0.001^{*}$ & $\begin{array}{c}18.892(3.235- \\
110.322)\end{array}$ \\
\hline
\end{tabular}

OR: Odd`s ratio

C.I: Confidence interval LL: Lower limit UL: Upper Limit

SAAG: serum-ascites albumin gradient

PCI: Portal congestion index

Model A: adjust Odd`s ratio by age and sex

Model B: adjust Odd`s ratio by age, sex, Hepatic encephalopathy, Splenic collaterals, platelet count and Child Pough Score

\section{DISCUSSION}

Cirrhosis of the liver has become a leading cause of morbidity as well as mortality. It was previously recorded by the Global Burden of Disease (GBD) that nearly one million people died from cirrhosis in 2010 around the world, compared with 676,000 deaths in 1980 . Because cirrhosis has a low survival rate, data on the incidence of geographical variations is critical for preventing disability and mortality. However, because relevant data for 58/187(31\%) of countries was not accessible in the report, the severity of this medical issue may be substantially greater [12].

The burden of liver cirrhosis is increasing in both the West and the East, according to existing information. From 1980 to 2010, the number of deaths due by liver cirrhosis throughout the Caribbean, Oceania, Africa, Latin America, Asia, and Europe had raised dramatically. Besides, Egypt had the highest age-standardized mortality rate related to cirrhosis [13].

Existing evidence showed that, liver cirrhosis is considered to be end-stage of diverse chronic 
liver diseases, and is often neglected till complications, as ascites, spontaneous bacterial peritonitis (SBP), variceal haemorrhage, or hepatic encephalopathy occur [14]. EV are found in around half of all cirrhotic individuals at the time of diagnosis. Varices grow from small to large at a rate of 5-12 percent per year and bleed at a rate of 5-12 percent per year once they have formed [15]. When varices first occur in patients with compensated cirrhosis, it suggests that the illness has progressed from a low-risk to an intermediate-risk stage. As bleeding occurs, it signifies decompensation and progression to a high risk of death [16].

When liver cirrhosis is detected, many studies recommended that cirrhotic patients should be screened for the existence of EV [15, 17], while endoscopy is an invasive and unpleasant procedure that carry rare but serious complications as well [18]. As a result, several scholars have sought to estimate the degree of esophageal varicosity using noninvasive indicators rather than endoscopy including liver stiffness assessment, platelet count in addition to platelet count/spleen size and spleen stiffness $[19,20]$. However, there is no worldwide agreement on which variable is best for forecasting the risk of EV.

In the present study, cirrhotic patients with esophageal varices had lower platelet count than those without esophageal varices. This finding agreed with Thomopoulos and his colleague who reported that the existence of EV in patients with liver cirrhosis could be predicted by low platelet count [21]. They concluded that, Platelets <118.000 in cirrhotic patients could predict the presence of EV. The reduction of Platelets may be related to splenic sequestration of platelets, reduced thrombopoietin production, and myelosuppression of platelet production [22].

In the past 20 years, the serum ascites albumin gradient (SAAG), has been proposed as a reliable marker for differential diagnosis of ascites as well as a predictor of portal hypertension [23].

Regarding serum albumin, our study showed that, cirrhotic patients with EV showed lower serum albumin than those without esophageal varices. Moreover, ascitic fluid albumin was significantly lower in cirrhotic patients with EV than in cirrhotic patients without EV. In addition, our results documented that, there was a statistically significant difference between the two groups regarding SAAG. Group II; cirrhotic patients with EV had higher SAAG values (1.85 $\pm 0.24)$ than Group I $(1.27 \pm 0.15)$.

These results were in accordance with previous literature where low serum albumin was found in patients with esophageal varices than those without [24]. Furthermore, additional reports exhibited that high SAAG reflects the presence of esophageal varices [25]. Also Thong et al, reported that patients with EV showed significantly higher SAAG compared with cirrhotic patients without EV (mean SAAG values were 2.012 and 1.33 respectively) [26].

Regarding splenic collaterals and the portal vein cross section area, our study showed that, cirrhotic patients with esophageal varices showed more frequent splenic collaterals than in cirrhotic patients without esophageal varices $(73.6 \%$ and $39.5 \%$ respectively), moreover higher cross section area was found in cirrhotic patients with esophageal varices.

A previous report on portal vein diameter and splenic collaterals in cirrhotic patients has concluded that, portal vein dilatation ( $\geq 14.9 \mathrm{~mm}$ ), and presence of splenic collaterals by ultrasound can predict EV specially the large varices and explained portal vein dilation by presence of the spleno-portal veins which increase in caliber with worsening of portal hypertension and decompression of these veins by opening shunts with systemic circulation (i.e varices) [27].

The current study addressed SAAG as a useful predictive biomarker of esophageal varices for patients with cirrhosis ascites. ROC curve for SAAG for detection of esophageal varices: AUC was 0.986 ( $p<0.001)$ with Cut off $>1.4$ had a high ability to predict esophageal varices in cirrhotic patients with Sensitivity $97.70 \%$ and Specificity of $89.47 \%$.

Our results are near to the results obtained by Marakbi et al. [28] they found that at cut-off value of $\geq 1.3 \mathrm{gm} / \mathrm{dl}$ SAAG could predict the presence of esophageal varices in cirrhotic patients, with specificity (100\%), sensitivity $(90.09 \%)$, positive predictive value (PPV) was $100 \%$ and negative predictive value (NPV) was $64.5 \%$.

While these results disagree with those of Gurubacharya and colleagues who reported that esophageal varices are present in all patients with SAAG value above $2.0 \mathrm{gm} / \mathrm{dl}$ [23]. This 
difference in the results as regard cut-off value of SAAG level as an accurate indicator for the presence of esophageal varices can be attributed to the difference in the population samples. In our study all patients had ascites related to viral infection (chronic HCV and chronic HBV) while in other study; most of the patients with high SAAG had alcoholic liver cirrhosis.

The PCI described by Moriyasu et al. has been used to diagnose cirrhosis and portal hypertension [11]. It demonstrates the increase in the cross-sectional area of the Portal Vein and the reduction in velocity. PCI is estimated from the ratio of the Vein cross-sectional area $(\mathrm{cm} 2)$ and the average flow velocity $(\mathrm{cm} / \mathrm{sec})$, with $\leq$ $0.07 \mathrm{~cm} / \mathrm{sec}$ deemed to be normal value.

In the present study, cirrhotic patients with esophageal varices showed a higher PCI than cirrhotic patients without esophageal varices. Also ROC curve for portal congestion index for the detection of esophageal varices: AUC of portal congestion index was 0.974 ( $p<0.001)$ with Cut off $>0.135$ had a high ability to predict esophageal varices in cirrhotic patients with sensitivity $90.80 \%$ and specificity of $94.74 \%$. These results are in agreement with those reported by Hekmatnia et al. and Leão et al. where the index was significant in prediction of the presence of EV [29,30].

Several cut off points for the PCI were reported, Nouh et al. found that, at cutoff point 0.11 , the sensitivity of PCI to predict EV was $93 \%$, the specificity was $85.7 \%$, and AUC was 0.889 . [31] Furthermore Moriyasu et al. found that, PCI cutoff point was (0.189) in patients with EV with sensitivity $(84.65 \%)$ [11]. The differences in the cutoff point of PCI in these studies could be attributed to the inter-observer variability or the wide range of velocities obtained when the Doppler angle is changed from 0 to 60 degrees.

In the present study, ROC curve of the combination of both SAAG and PCI for detection of esophageal varices showed a high ability to predict esophageal varices in cirrhotic patients. Additionally, analyzing the risk association of PCI and SAAG, both could be considered as risk factors for prediction of esophageal varices in cirrhotic patients with ascites.

Analyzing the risk association of both SAAG with the presence of esophageal varices, our study explored the significance of SAAG as independent risk factor to predict the presence of esophageal varices. Similarly, Thong and colleagues found in multivariate analysis that SAAG was an independent predictor of esophageal varices detected on endoscopy results with $\mathrm{p}$ value $<0.05[\mathbf{2 6}]$.

\section{CONCLUSION}

The current study suggests that SAAG could be used as a non-invasive predictor for the presence of $\mathrm{OV}$ in cirrhotic patients along with SAAG with Cut off $>1.4$ requiring clinical attention. Additionally, congestion index with Cut off $>0.135$ had a high ability to predict the existence of esophageal varices (EV) in cirrhotic patients. Additionally, our study has confirmed that in medical centers where endoscopic assessment is not accessible, noninvasive indices as SAAG and PCI may be valuable tools for predicting the existence of esophageal varices in patients with liver cirrhosis, regardless of Child-Pugh grade. As a result, the studied indices could guide the decision to initiate primary prophylaxis.

\section{Abbreviations}

EGD: esophagogastroduodenoscopy, SAAG: serum ascites albumin gradient, EV: esophageal varices, PCI: portal vein congestion index, ALT: Alanine aminotransferase, AST: aspartate aminotransferase, INR: international normalized ratio, HVPG: hepatic venous pressure gradient.

\section{Ethics approval and consent to participate}

The study was carried out after approval from the Faculty of Medicine Ethical Committee, Menoufia University, Egypt. For all participants an explanation about the study was provided together with informed written consent was obtained from each one before enlisted in the study.

\section{Competing interests}

The authors declare that they have no competing interests.

\section{Funding}

Not applicable. The study was fully non-funded from any organization.

\section{REFERENCES}

1. Hadjihambi A, Arias N, Sheikh M, Jalan R. Hepatic encephalopathy: a critical current review. Hepatol Int. 2018 Feb; 12(Suppl 1):135-147. doi: 
10.1007/s12072-017-9812-3. Epub 2017 Aug 2. PMID: 28770516 ; PMCID: PMC5830466.

2. Villanueva C, Colomo A, Bosch A, Concepción M, Hernandez-Gea V, Aracil C, et al. Transfusion strategies for acute upper gastrointestinal bleeding. $N$ Engl J Med. 2013 Jan 3; 368(1):11-21. doi: 10.1056/NEJMoa1211801. Erratum in: N Engl J Med. 2013 Jun 13;368(24):2341. PMID: 23281973.

3. Al-Busafi SA, McNabb-Baltar J, Farag A, Hilzenrat N. Clinical manifestations of portal hypertension. Int J Hepatol. 2012; 2012:203794. doi: 10.1155/2012/203794. Epub 2012 Sep 17. PMID: 23024865; PMCID: PMC3457672.

4. Suk KT. Hepatic venous pressure gradient: clinical use in chronic liver disease. Clin Mol Hepatol. 2014 Mar; 20(1): 6-14. doi: 10.3350/cmh.2014.20.1.6. Epub 2014 Mar 26. PMID: 24757653; PMCID: PMC3992331.

5. Guha IN, Myers RP, Patel K, Talwalkar JA. Biomarkers of liver fibrosis: what lies beneath the receiver operating characteristic curve? Hepatology. 2011 Oct; 54(4):1454-62. doi: 10.1002/hep.24515. Epub 2011 Aug 9. PMID: 21725995.

6. Haq I, Tripathi D. Recent advances in the management of variceal bleeding. Gastroenterol Rep (Oxf). 2017 May; 5(2):113-126. doi: 10.1093/gastro/gox007. Epub 2017 Apr 7. PMID: 28533909; PMCID: PMC5421505.

7. Moore KP, Wong F, Gines P, Bernardi M, Ochs A, Salerno F, et al. The management of ascites in cirrhosis: report on the consensus conference of the International Ascites Club. Hepatology. 2003 Jul; 38(1):258-66. doi: 10.1053/jhep.2003.50315. PMID: 12830009.

8. Moriyasu F, Ban N, Nishida O, Nakamura T, Koizumi S, Sakai M, et al. Quantitative measurement of portal blood flow in patients with chronic liver disease using an ultrasonic Duplex system consisting of a pulsed Doppler flowmeter and B-mode electroscanner. Gastroenterol Jpn. 1984 Dec;19(6):529-36. doi: 10.1007/BF02793866. PMID: 6098510.

9. Westaby D, Hayes PC, Gimson AE, Polson RJ, Williams R. Controlled clinical trial of injection sclerotherapy for active variceal bleeding. Hepatology. 1989 Feb;9(2):274-7. doi: 10.1002/hep.1840090219. PMID: 2492252.

10. Khandwalla HE, Fasakin Y, El-Serag HB. The utility of evaluating low serum albumin gradient ascites in patients with cirrhosis. Am J Gastroenterol. 2009 Jun;104(6):1401-5. doi: 10.1038/ajg.2009.117. Epub 2009 Apr 21. PMID: 19491852.
11. Moriyasu F, Nishida O, Ban N, Nakamura T, Miura K, Sakai M, et al. Measurement of portal vascular resistance in patients with portal hypertension. Gastroenterology. 1986 Mar;90(3):710-7. doi: 10.1016/00165085(86)91127-3. PMID: 2935445.

12. Mokdad AA, Lopez AD, Shahraz S, Lozano R, Mokdad AH, Stanaway J, et al. Liver cirrhosis mortality in 187 countries between 1980 and 2010: a systematic analysis. BMC Med. 2014 Sep 18;12:145. doi: 10.1186/s12916-014-0145-y. PMID: 25242656; PMCID: PMC4169640.

13. Byass P. The global burden of liver disease: a challenge for methods and for public health. BMC Med. 2014 Sep 18;12:159. doi: 10.1186/s12916014-0159-5. PMID: 25286285; PMCID: PMC4168048.

14. Nusrat S, Khan MS, Fazili J, Madhoun MF. Cirrhosis and its complications: evidence based treatment. World J Gastroenterol. 2014 May 14; 20(18):5442-60. doi: 10.3748/wjg.v20.i18.5442. PMID: 24833875; PMCID: PMC4017060.

15. Garcia-Tsao G, Sanyal AJ, Grace ND, Carey W; Practice Guidelines Committee of the American Association for the Study of Liver Diseases; Practice Parameters Committee of the American College of Gastroenterology. Prevention and management of gastroesophageal varices and variceal hemorrhage in cirrhosis. Hepatology. 2007 Sep; 46(3):922-38. doi: 10.1002/hep.21907. Erratum in: Hepatology. 2007 Dec;46(6):2052. PMID: 17879356.

16. Smith JL, Graham DY. Variceal hemorrhage: a critical evaluation of survival analysis. Gastroenterology. 1982 May; 82(5 Pt 1):968-73. PMID: 7037525.

17. de Franchis R; Baveno V Faculty. Revising consensus in portal hypertension: report of the Baveno V consensus workshop on methodology of diagnosis and therapy in portal hypertension. $J$ Hepatol. 2010 Oct; 53(4):762-8. doi: 10.1016/j.jhep.2010.06.004. Epub 2010 Jun 27. PMID: 20638742.

18. Hwang JH, Shergill AK, Acosta RD, Chandrasekhara V, Chathadi KV, Decker GA, et al. The role of endoscopy in the management of variceal hemorrhage. Gastrointest Endosc. 2014 Aug; 80(2):221-7. doi: 10.1016/j.gie.2013.07.023. PMID: 25034836.

19. Rockey DC, Elliott A, Lyles T. Prediction of esophageal varices and variceal hemorrhage in patients with acute upper gastrointestinal bleeding. J Investig Med. 2016 Mar;64(3):745-51. doi: 10.1136/jim-2015-000047. Epub 2016 Feb 12. PMID: 26912006. 
20. Takuma Y, Nouso K, Morimoto Y, Tomokuni J, Sahara A, Takabatake $\mathrm{H}$, et al. Prediction of oesophageal variceal bleeding by measuring spleen stiffness in patients with liver cirrhosis. Gut. 2016 Feb;65(2):354-5. doi: 10.1136/gutjnl2015-309741. Epub 2015 May 25. PMID: 26006115 .

21. Thomopoulos KC, Labropoulou-Karatza C, Mimidis KP, Katsakoulis EC, Iconomou G, Nikolopoulou VN. Non-invasive predictors of the presence of large oesophageal varices in patients with cirrhosis. Dig Liver Dis. 2003 Jul;35(7):4738. doi: 10.1016/s1590-8658(03)00219-6. PMID: 12870732

22. Ramadori P, Klag T, Malek NP, Heikenwalder M. Platelets in chronic liver disease, from bench to bedside. JHEP Rep. 2019 Oct 25;1(6):448-459. doi: $\quad 10.1016 /$ j.jhepr.2019.10.001. PMID: 32039397; PMCID: PMC7005648.

23. Gurubacharya DL, Mathura KC, Karki DB. Correlation between serum-ascites albumin concentration gradient and endoscopic parameters of portal hypertension. Kathmandu Univ Med J $(K U M J) .2005$ Oct-Dec;3(4):327-33. PMID: 16449830 .

24. Sheta EA, Yousef M, Abd-Elsalam S, Mohamed REE, Ismail A, El-Kalla $\mathrm{F}$ et al. Non Invasive Diagnosis of Esophageal Varices: Can it Replace Screening Endoscopy? Intrenational Journal of Current Microbiology and applied science. 2016; 5 (5): 701-15.

25. Begum N, Afroza A, Karim BM. Evaluation of correlation between high serum-ascites albumin gradient and the upper gastrointestinal endoscopic parameters in children presenting with portal hypertension with ascites. Mymensingh Med J. 2014 Oct;23(4):703-8. PMID: 25481588.
26. Thong VD, Anh HTV. Prediction of Esophageal Varices Based on Serum-Ascites Albumin Gradient in Cirrhotic Patients. Gastroenterology Insights. 2021; 12(2):270-277. https://doi.org/10.3390/gastroent12020023

27. Ismail FW, Shah HA, Hamid S, Abbas Z, Abid S, Mumtaz K, Jafri W. Noninvasive predictors of large varices in patients hospitalized with gastroesophageal variceal hemorrhage. Hepatol Int. 2008 Mar;2(1):124-8. doi: 10.1007/s12072007-9034-1. Epub 2007 Dec 14. PMID: 19669288; PMCID: PMC2716872.

28. Marakbi A, Abdalla T, abdelmonem S, Pasha H. Prediction of Oesophageal Varices in Cirrhotic Patients by Serum- Ascites Albumin Gradient. Zagazig University Medical Journal, 2020; 26(1): 99-107. doi: 10.21608/zumj.2019.16241.1465

29. Hekmatnia A, Barikbin R, Farghadani M, Omidifar N, Adibi, P. Prediction and screening of esophageal varices in cirrhotic patients using doppler US hemodynamic indices of portal system. Gastroenterology Insights. 2011, 3 (1). doi: 10.4081/gi.2011.e4

30. Leão J, Brock M, Castilho M, Scariot A, Scariot A, Braga W. Non-invasive assessment of fibrosis using color Doppler ultrasound in patients with hepatitis $\mathrm{C}$ virus in the Amazon rainforest, Brazil. Am J Trop Med Hyg. 2012 Feb;86(2):273-9. doi: 10.4269/ajtmh.2012.11-0561. PMID: 22302863; PMCID: PMC3269281.

31. Nouh MA, El-Hammoly MS, Mohamed SA, Hana MM. The role of portal congestion index in prediction of esophageal varices in hepatitis $\mathrm{C}$ virus-infected patients. Menoufia Med $J$ 2019;32:1119-25 